\title{
Molecular analyses of gut contents: elucidating the feeding of co-occurring salps in the Lazarev Sea from a different perspective
}

\author{
KATJA METFIES ${ }^{1,2}$, ANJA NICOLAUS $^{1}$, LENA VON HARBOU ${ }^{1}$, ULRICH BATHMANN $^{1,3}$ and \\ ILKA PEEKEN ${ }^{1,4}$ \\ ${ }^{1}$ Alfred Wegener Institute for Polar and Marine Research, Am Handelshafen 12, 27570 Bremerhaven, Germany \\ ${ }^{2}$ Jacobs University Bremen, Campus Ring 1, 28759 Bremen, Germany \\ ${ }^{3}$ Leibniz-Institute for Baltic Sea Research, Seestrasse 15, 18119 Rostock, Germany \\ ${ }^{4}$ MARUM - Center for Marine Environmental Sciences, University of Bremen, 28334 Bremen, Germany \\ Katja.Metfies@awi.de
}

\begin{abstract}
The diet of Antarctic salps was elucidated by investigating their gut content using automated ribosomal intergenic spacer analysis (ARISA) and 454-pyrosequencing. Salp samples were collected during the Lazarev Sea Krill Study in the western Weddell Sea (summer 2005-06 and 2007-08, autumn 2004 and winter 2006). Two salp species, Salpa thompsoni and Ihlea racovitzai, both occur in the Southern Ocean and can overlap geographically and seasonally. We provide evidence that, despite the non-selective feeding mechanism, the two co-occurring salp species might have different niches within a habitat. ARISA-patterns of 93 gut content samples revealed strong differences between the two salp species, even at the same sampling site. These differences were confirmed by 454-pyrosequencing of the V4-18S rDNA of ten salps. The pyrosequencing data indicate that flagellates, in particular dinophyceae, constitute a high proportion of the sequence reads identified in the gut content of both salp species. However, within the dinophyceae, differences in the read composition were detected between the two salp species. This supports the findings of a previous study where fatty acid signatures indicate a flagellate-based diet, even though microscopic analyses identified diatoms as the dominant component of salp gut contents.
\end{abstract}

Received 18 November 2013, accepted 11 February 2014, first published online 12 May 2014

Key words: 454-pyrosequencing, ARISA, diet, Ihlea racovitzai, Salpa thompsoni, Southern Ocean

\section{Introduction}

Polar regions harbour major biological resources and the polar oceans are highly productive despite high seasonal variability in environmental conditions. Salps are among the most important metazoans in the Southern Ocean (Pakhomov et al. 2002, Tanimura et al. 2008). The abundance of salps has increased during recent decades (Pakhomov et al. 2002, Atkinson et al. 2004). Due to their high water content, salps have a relative low energetic value for higher trophic levels (Dubischar et al. 2012). As a consequence, drastic changes in the pelagic food web structure, pathways of organic matter and feeding conditions of Antarctic vertebrates (e.g. seals, penguins, whales) should be expected if the dominance of salps continues (Nicol et al. 2008). Two salp species occur in the Southern Ocean. Salpa thompsoni (Foxton 1961) is adapted to oceanic conditions of the Antarctic Circumpolar Current (ACC) (Pakhomov et al. 2002) and is mainly found north of the southern boundary (Pakhomov et al. 2006). Ihlea racovitzai (Van Beneden \& Selys Longchamp 1913) is considered a cold water species occurring in higher Antarctic latitudes (Pakhomov et al. 2011). However, the two salp species can overlap geographically and seasonally (von Harbou et al. 2011, Ono \& Moteki 2013). Occasionally, intrusions of warm water masses transport $S$. thompsoni to higher latitudes (Pakhomov et al. 2011), and recent studies have reported a southward shift of $S$. thompsoni as ocean warming proceeds (Atkinson et al. 2004). As a consequence, there might be competition between the two species for phytoplankton, which may impact the distribution and survival of I. racovitzai. To date it remains unclear whether feeding behaviour or other mechanisms separate these two species in the same environment. Speciesspecific differences in food composition are unlikely as salps are typical filter feeders and by contracting their circumferential muscle bands they pump water through a fine-meshed filter that is continuously moved along their pharyngeal cavity and then ingested along with the trapped particles (Alldredge \& Madin 1982). Filtered water leaving the pharynx produces the thrust for jetpropelled swimming, such that feeding and swimming is a continuous process. Salp grazing can exert a significant impact on plankton communities (Tanimura et al. 2008). The salp diet and feeding strategy was investigated during the Lazarev Sea Krill Study (LAKRIS) by microscopic and fatty acid analyses (von Harbou et al. 2011). 
Microscopic analysis of gut contents suggested that the diets of $S$. thompsoni and I. racovitzai were similar, consisting mainly of diatoms, and displayed limited seasonality. In contrast, fatty acid analysis suggested that flagellates were the major component of the salp diet and that there were differences in diet between the two species. The generally high contribution of flagellate markers could reflect either a higher contribution of flagellates to the protist community in ambient waters or a higher digestibility of naked flagellates compared to diatoms.

In the Lazarev Sea, phytoplankton blooms are mainly composed of diatoms, while nano- and picoplankton generally dominate the background phytoplankton biomass (Pakhomov et al. 2002, Smetacek et al. 2004, Mendes et al. 2013). Various taxonomic groups within the flagellates, e.g. prasinophytes, dinoflagellates and cryptophytes, constitute important parts of the picoeukaryote communities (Diez et al. 2004, Metfies et al. 2010). Thus the flagellate signal observed in the fatty acid signature could be related to feeding on picoeukaryote flagellates. The assessment of picoeukaryotes by microscopy is challenging due to their cell size and limited morphological features.

The introduction of molecular techniques has facilitated the assessment of the community compositions of marine microbes, including picoeukaryotes (Wolf et al. 2013), even in the gut content of krill (Tobe et al. 2010). The genes coding for the ribosomal RNA (rRNA) are particularly well suited for phylogenetic analysis and taxonomic identification because they are universally present in all organisms. Furthermore, rRNA genes are of relatively large size and contain both highly conserved and variable regions with no evidence for lateral gene transfer (Woese 1987). Molecular fingerprinting methods targeting the ribosomal operon, e.g. automated ribosomal intergenic spacer analysis (ARISA) or terminal restriction fragment length polymorphism (T-RFLP) of ribosomal genes, are well-established, cost-effective tools for quick comparative analyses of microbial communities (Dunbar et al. 2000, Joo et al. 2010). ARISA is based on analysing the size of intergenic spacer regions of the ribosomal operon (Wolf et al. 2013), while T-RFLP focuses on the size of restriction fragments generated from a ribosomal gene (Joo et al. 2010). In both cases, the composite of the resulting DNA fragments in a sample is a characteristic fingerprint of a microbial community. However, it does not provide information on the species composition. The assessment of microbial species composition requires a more labour intensive sequencing of marker-genes, e.g. rRNA genes. The 454-pyrosequencing high-throughput approach allows assessment of microbial communities at high resolution, based on sufficiently deep taxon sampling (Margulies et al. 2005).

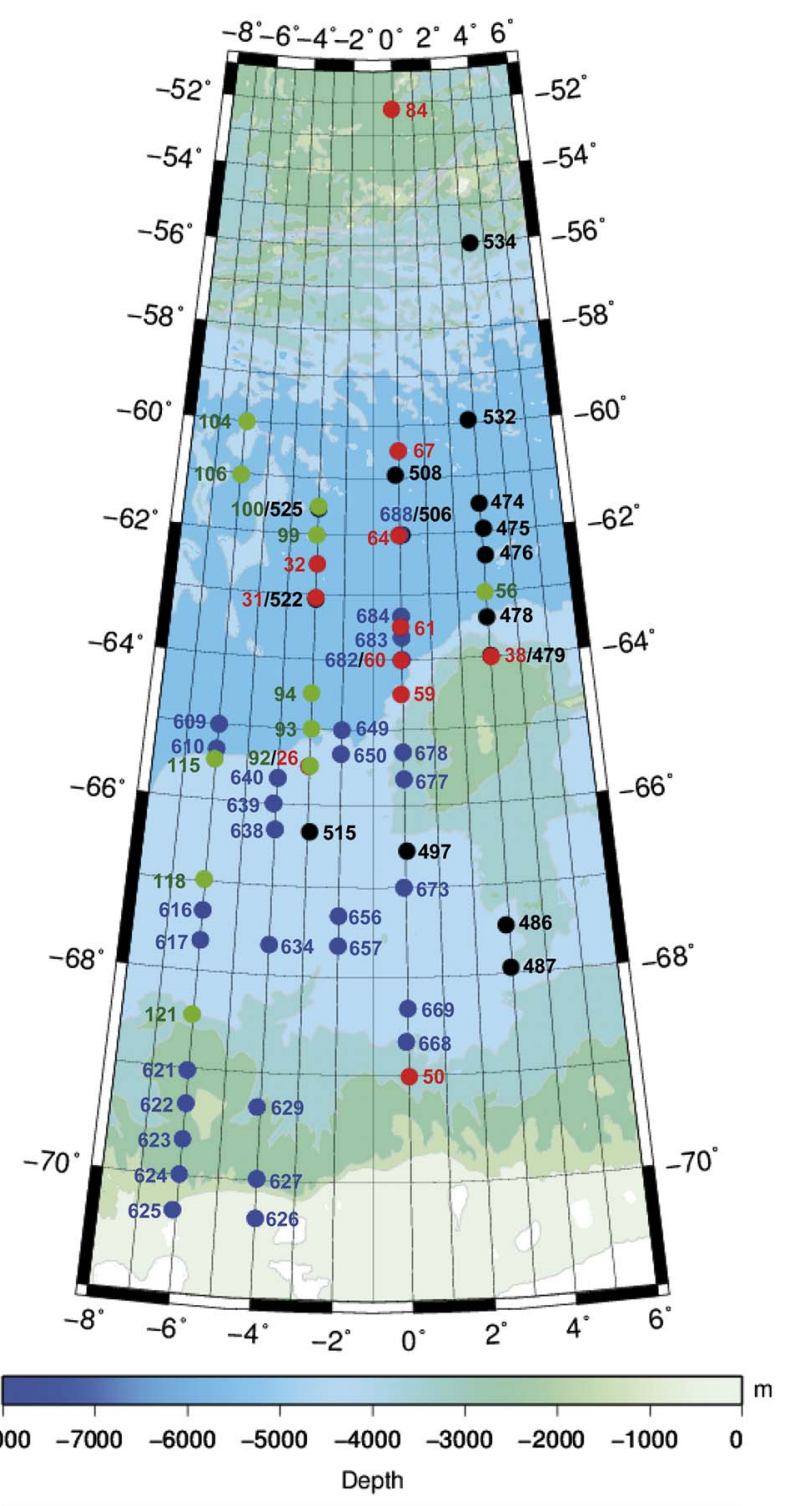

ANTXXI-4 ANTXXIII-2 ANTXXIII-6 ANTXXIV-2

Fig. 1. Map of the sampling sites in the Lazarev Sea during four cruises (ANT XXI/4, ANT XXIII/2, ANT XXIV/2, ANT XXIII/6).

The current study, as part of LAKRIS, was carried out to elucidate the feeding dynamics between the two salp species. We investigated salp gut contents using molecular methods that are independent of the size of the organism or morphological markers. This involved the application of molecular fingerprinting and 454-pyrosequencing of the $18 \mathrm{~S}$ rDNA V4-region. We hypothesized that the molecular analysis would show the presence of flagellates in the salp gut contents, as suggested by fatty acid data (von Harbou et al. 2011), the limited seasonality and the differences in the ingested food composition between S. thompsoni and I. racovitzai. 


\section{Material and methods}

Samples

The salp samples were collected in the Lazarev Sea (eastern Weddell Sea) on board the RV Polarstern for LAKRIS during autumn 2004 (ANT XXI/4), summer 2005-06 (ANT XXIII/2), summer 2007-08 (ANT XXIV/2) and winter 2006 (ANT XXIII/6) (Fig. 1 and Table S1 found at http://dx.doi.org/10.1017/S0954102014000157).

The salps were collected using a multiple rectangular midwater trawl type RMT8+1 harnessed with 4.5- and $0.3-\mathrm{mm}$ mesh nets at a tow speed of $c .2 .5 \mathrm{~km} \mathrm{~h}^{-1}$. The net tows were completed as double oblique hauls in the upper $200 \mathrm{~m}$ of the water column. Subsequent to sampling the salps were kept frozen at $-4-80^{\circ} \mathrm{C}$. Details of the sampling procedure are described by Pakhomov et al. (2011) and von Harbou et al. (2011). The original study did not carry out molecular analysis, thus the samples analysed in this study are a limited set that were still available. To avoid size-dependant variation in the gut contents only solitary animals between $1.5-3 \mathrm{~cm}$ were used. Samples were thawed and the guts were dissected from the animals. The resulting gut content samples were frozen at $-80^{\circ} \mathrm{C}$ until DNA extraction. We cannot exclude that the two freezing and thawing cycles might impact the integrity of the genomic DNA, i.e. DNA might be more vulnerable to fragmentation (Fraser et al. 2011). This is a random process that probably does not impact the overall structure of the phytoplankton communities in the salp guts.

\section{Isolation DNA}

In total 93 specimens (52 S. thompsoni and 41 I. racovitzai) were used to extract genomic DNA from the gut contents. The extraction was carried out with the EZNA ${ }^{\circledR}$ SP Plant DNA Mini Kit (Omega Bio-Tek) according to a slightly modified manufacturer's protocol. This included an optimization of the elution step. The amount of genomic DNA isolated from the samples was maximized by incubating $30 \mu \mathrm{l}$ elution buffer for 5 minutes on the column, retransferring the eluate and repeating the elution step. Spectrophotometric quantification of DNA was performed with the NanoDrop ${ }^{\mathbb{R}}-1000$ spectrophotometer (NanoDrop Products, Wilmington, DE).

\section{Automated ribosomal intergenic spacer analysis}

The intergenic spacer region of the ribosomal operon was amplified from the genomic DNA using the primers 1528F 5'-GTAGGTGAACCTGCAGAAGGATCA-3' and ITS2 5'-GCTGCGTTCTTCATCGATGC-3'. Primer $1528 \mathrm{~F}$ had at least one mismatch against the $18 \mathrm{~S}$ rDNA of each salp species and was fluorescently labelled with 6-FAM. The PCR-amplifications were performed with a $20 \mu$ volume in a thermal cycler (Eppendorf) using 1x HotMaster Taq buffer with $\mathrm{Mg}^{2+} 2.5 \mathrm{mM}$ (5 Prime), $0.02 \mathrm{U}$ HotMaster Taq DNA polymerase (5 Prime), $0.4 \mathrm{mg} \mathrm{ml}^{-1}$ bovine serum albumin (BSA), $0.8 \mathrm{mM}$ (of each) deoxynucleotide triphosphates (dNTP; Eppendorf), $0.2 \mu \mathrm{M}$ of each primer and $1 \mu \mathrm{l}$ of template DNA $\left(20 \mathrm{ng} \mu^{-1}\right)$. The amplification was based on 35 cycles, consisting of $94^{\circ} \mathrm{C}$ for 45 seconds, $55^{\circ} \mathrm{C}$ for 1 minute and $72^{\circ} \mathrm{C}$ for 3 minutes, preceded by 3 minutes denaturation at $94^{\circ} \mathrm{C}$ and followed by a final extension of 10 minutes at $72^{\circ} \mathrm{C}$. The PCR fragment sizes were determined by an analysis with a capillary sequencer (ABI 3130xL, Applied Biosystems). The ARISA was carried out in three replicates for each sample. Quality control and the data analysis were carried out with the GeneMapper v4.0 software (Applied Biosystems). This included the application of a $50 \mathrm{bp}$ threshold for counting peaks to exclude false positive peaks originating from primers or by the formation of primer dimers.

\section{Statistical analyses of automated ribosomal intergenic spacer analysis}

In an ARISA, the community is characterized by the composition (presence/absence) of different DNA fragment sizes. The DNA fragments are a result of the amplification of the internal transcribed spacer region of the ribosomal operon, which displays a high degree of taxon-related variability in its length. In this study, presence/absence matrices, reflecting the community profiles of the samples, were generated by binning the quality controlled raw data obtained after size separation with the capillary sequencer using the 'Interactive Binner' (http://www.mpi-bremen.de/ en/Software_2.html). Differences in the ARISA community profiles were estimated by calculating the Jaccard index, which is a statistical method used for comparing the similarity and diversity of sample sets. It measures the similarity between samples. The result of the analysis was a distance matrix of the samples in the dataset, which was visualized by multidimensional scaling (MDS) using the vegan software package (http://r-forge.r-project.org/ projects/vegan/). Groups in the MDS plot were determined a priori. The significance of the grouping was tested by analysing the similarity between the groups with an ANOSIM. An ANOSIM is a multivariate, non-parametric statistical method used for comparing community compositions among groups of samples. All statistical analyses were carried out within the R-package (http://www.R-project.org/).

\section{4-Pyrosequencing}

Extracted DNA was used as a template for the amplification of the 18S rDNA V4-region using the primers $528 \mathrm{~F}$ 5'-GCGGTAATTCCAGCTCCAA-3' (Medlin et al. 2006) and 690R 5'-ATCCAAGAATTTCACCTCTGA-3' 
(Metfies \& Medlin 2008). The reverse primer had one mismatch against the 18S rDNA of each salp species in order to avoid amplification of the grazer rDNA. All PCRs were performed in a final volume of $50 \mu \mathrm{l}$ and contained: $0.02 \mathrm{U}$ HotMaster Taq polymerase (5 Prime), the 10-fold polymerase buffer according to manufacturer's specification, $0.4 \mathrm{mg} \mathrm{ml}^{-1}$ BSA, $0.8 \mathrm{mM}$ (of each) dNTP (Eppendorf), $0.2 \mu \mathrm{M}$ of each primer and $1 \mu \mathrm{l}$ of template DNA. The PCR amplification was performed in a thermal cycler (Eppendorf) with an initial denaturation $\left(94^{\circ} \mathrm{C}, 5\right.$ minutes) followed by 35 cycles of denaturation $\left(94^{\circ} \mathrm{C}, 1\right.$ minute), annealing $\left(58^{\circ} \mathrm{C}, 2\right.$ minutes $)$ and extension $\left(72^{\circ} \mathrm{C}, 2\right.$ minutes) with a single final extension $\left(72^{\circ} \mathrm{C}, 10\right.$ minutes). The PCR products were purified by the application of the Mini Elute PCR Purification kit (QIAgen). Sequencing of the amplicon was performed by GATC Biotech, Germany, using a 454 GS FLX sequencer (Roche). Supported sequences had an approximate length of $310 \mathrm{bp}$. Singletons were removed after assembling all sequences with the software Lasergene Seqman Pro (DNASTAR). The construction of artificial taxonomic subdivisions was based on an identity threshold of $97 \%$ on the $18 \mathrm{~S}$ rRNA gene in addition to a $50 \mathrm{bp}$ match size.

\section{Data analysis of the 454-pyrosequencing}

Raw sequence reads were processed to obtain high quality reads. The primer set used in this study amplified a PCR product of $c .500 \mathrm{bp}$ including the V4-region of the $18 \mathrm{~S}$
rRNA gene. The forward primer $528 \mathrm{~F}$ attached c. $25 \mathrm{bp}$ upstream of the V4-region, which had an approximate length of $230 \mathrm{bp}$ (Nickrent \& Sargent 1991). Thus, reads with a length $<300 \mathrm{bp}$ were excluded from further analysis to ensure inclusion of the complete V4-region and to exclude short reads. Unusually long reads, greater than the expected amplicon size (>670 bp), and reads with more than one uncertain base $(\mathrm{N})$ were also removed from the analyses. Chimeric sequences in the remaining dataset were eliminated from further analyses based on an assessment using the software UCHIME 4.2 (Edgar et al. 2011). The resulting high quality reads of all gut content samples were clustered into operational taxonomic units (OTUs) at the $97 \%$ similarity level using the software Lasergene 10 (DNASTAR). Subsequently, reads not starting with the forward primer were manually removed. Consensus sequences of each OTU were generated. This reduced the amount of sequences to operate with. However, it attenuated the influence of sequencing errors and uncertain bases. The $97 \%$ similarity level is the most suitable for reproducing original microbial diversity (Behnke et al. 2010) and has the effect of bracing most of the sequencing errors (Kunin et al. 2010). The OTUs that comprised only one sequence (singletons) were removed. The consensus sequences were aligned using the software HMMER 2.3.2 (Finn et al. 2011). Subsequently, taxonomic affiliation was determined by placing the consensus sequences into a reference tree, containing around 1200 high quality sequences of Eukarya from the SILVA reference

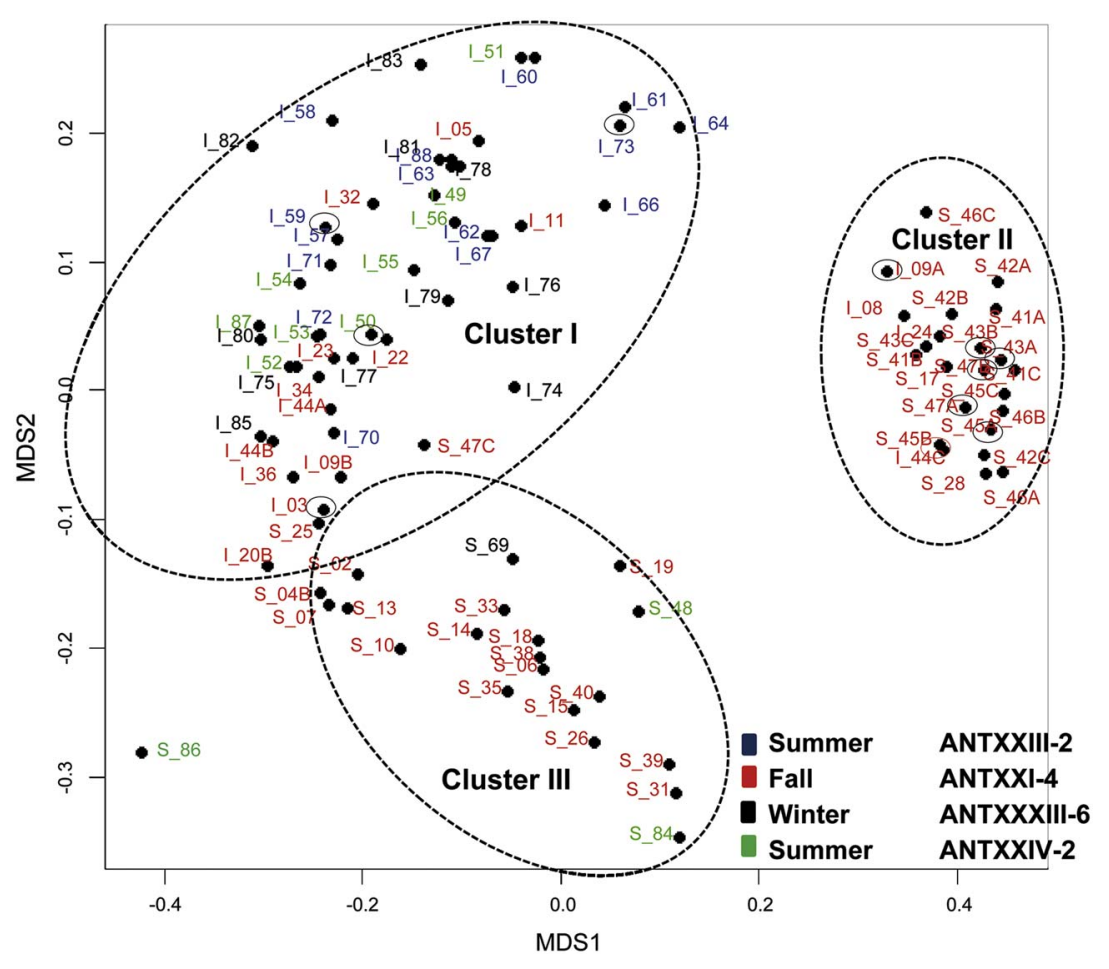

Fig. 2. MetaMDS-plot of differences between the ARISA profiles generated from the salp gut contents. Differences were calculated using the Jaccard index. 
database (SSU Ref 108), using the software pplacer 1.0 (Matsen et al. 2010). The OTUs assigned to fungi and metazoans were excluded from the analysis. Rarefaction curves were computed using the freeware program Analytic Rarefaction 1.3.

The sequences generated in this study have been deposited at the GenBank short read archive (accession SRA109294).

\section{Results}

\section{Automated ribosomal intergenic spacer analysis}

The genomic DNA from 93 salp gut content samples was subjected to ARISA. Based on the Jaccard index distances the ARISA profiles group into three distinct clusters in a metaMDS-plot (Fig. 2). The community profiles within a cluster are more similar to each other than to the community profiles of the other clusters. The clustering is supported by an ANOSIM $(r=0.46$, $P=0.001$ ). However, the clustering of the samples is not correlated to sampling seasons or cruises. Cluster I contains 50 I. racovitzai specimens and two $S$. thompsoni, collected across all four cruises. Cluster II contains four I. racovitzai specimens and 19 S. thompsoni, sampled during the autumn 2004 cruise. Cluster III contains 20 $S$. thompsoni specimens collected during three different cruises.

Variability in the gut contents of specimens collected at the same sampling site was assessed at thirteen locations (Table S1). At ten stations, specimens of both
S. thompsoni and I. racovitzai were available. At six stations, three specimens were available for S. thompsoni and $I$. racovitzai. At one station, there were two I. racovitzai specimens available. The ARISA profiles from specimens of the same species collected at the same sampling site (e.g. S_43A-C, S_42A-C or I_44A-B) are located in close proximity on the metaMDS-plot, suggesting that the gut contents were similar. In contrast, $S$. thompsoni and $I$. racovitzai specimens collected at the same sampling site were positioned in different clusters (Fig. 2). Differences between $S$. thompsoni and I. racovitzai were assessed by analysing the gut contents of both species from ten sampling sites (Table S1). The ARISA profiles suggest that the gut contents of $S$. thompsoni and I. racovitzai were significantly different at the majority of the ten sampling sites (Fig. 2).

In order to test the impact of spatial distribution and environmental conditions on the clustering of the ARISA profiles we carried out Mantel-Tests. The tests did not show a significant correlation (data not shown). Thus the clustering of the ARISA profiles could not be explained by spatial distribution or the available ambient environmental parameters (ice, temperature and ice coverage).

\section{4-Pyrosequencing}

A high-resolution, taxon-specific analysis of the gut contents of five I. racovitzai specimens collected across all four cruises and five $S$. thompsoni specimens collected

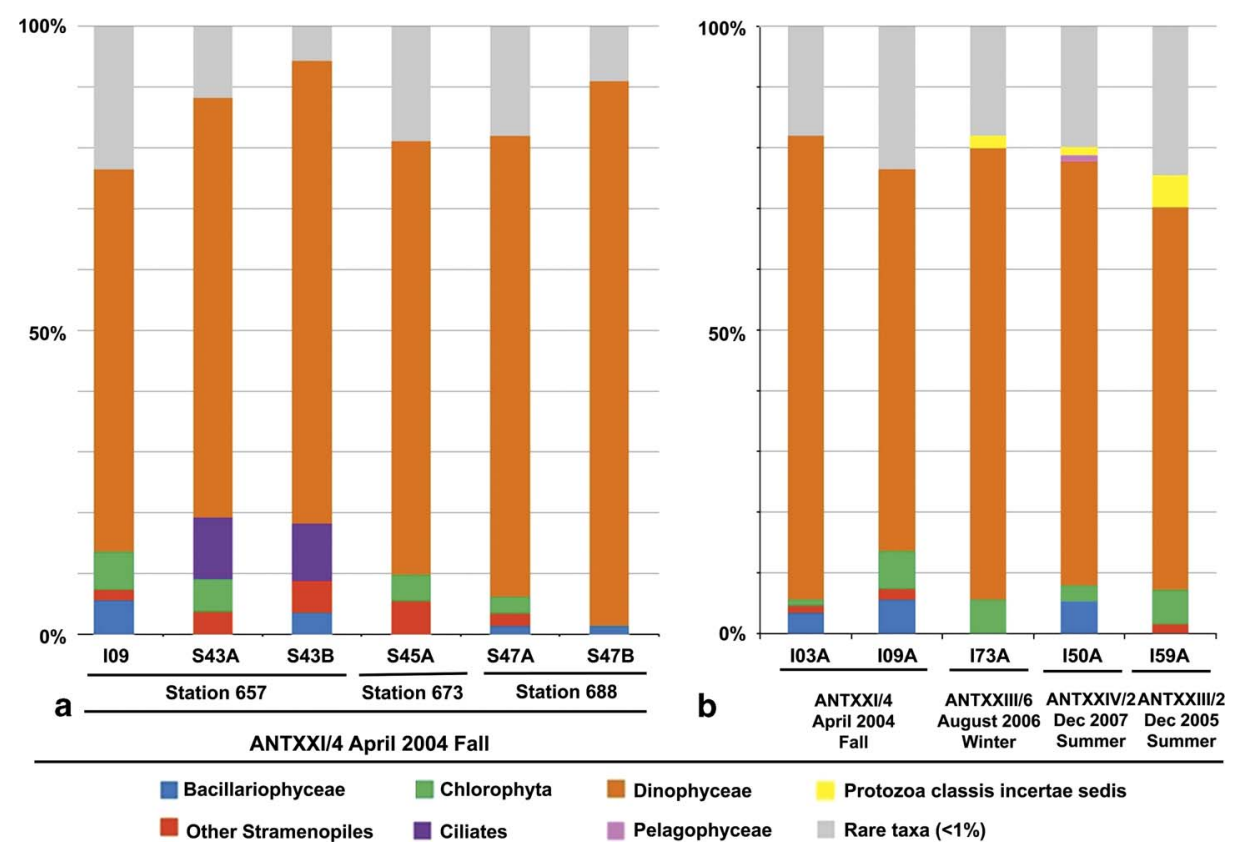

Fig. 3. Results of the 454-pyrosequencing of the $18 \mathrm{~S}$ rDNA V4-region amplified from the gut contents of $S$. thompsoni and $I$. racovitzai. The diagrams include all taxonomic groups identified in the dataset. a. Comparison of $18 \mathrm{~S}$ rDNA composition in the gut contents of one I. racovitzai specimen and five $S$. thompsoni specimens collected during ANT XXI/4 to elucidate differences in the ingested food signal of the two salp species. b. Comparison of the 18S rDNA composition in the gut contents of four I. racovitzai specimens collected across all four cruises (ANT XXI/4, ANT XXIII/2, ANT $\mathrm{XXIV} / 2$, ANT XXIII/6) to elucidate seasonal patterns in the ingested food signal of this salp species. 
during the autumn cruise was carried out by 454-pyrosequencing of the 18S rDNA V4-region (Fig. 3). A total of 12578 raw reads with $c .1000$ raw reads per sample were obtained. Subsequent to quality filtering, the raw reads clustered into 201 OTUs. The number of OTUs per sample was highest within sample I_09A (112 OTUs) and lowest in sample S_43B (ten OTUs). Due to the
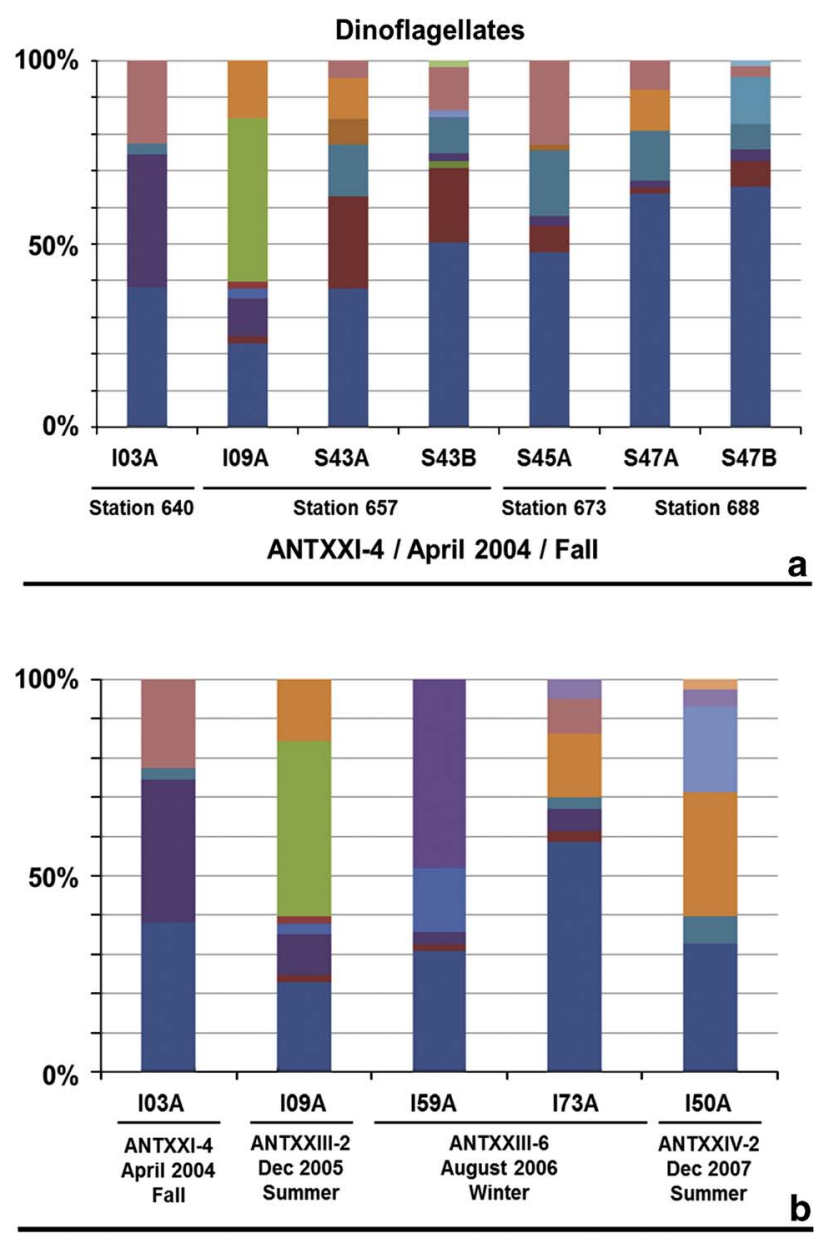

Uncultured Dinophyceae Type 53 Uncultured Dinophyceae Type 31 Encultured Dinophyceae Type 52 Uncultured Dinophyceae Type 30 - Uncultured Dinophyceae Type 50 - Uncultured Dinophyceae Type 29 Encultured Dinophyceae Type 46 Uncultured Dinophyceae Type 26 صncultured Dinophyceae Type 37 Encultured Dinophyceae Type 21 Encultured Dinophyceae Type 36 Uncultured Dinophyceae Type 18 - Uncultured Dinophyceae Type 34 Encultured Dinophyceae Type 01

Encultured Dinophyceae Type 33 a Dino Group II

E Uncultured Dinophyceae Type 32 =Dino Group I

Fig. 4. Results of the 454-pyrosequencing with special focus onto dinophyceae (dinoflagellates). a. Comparison of the dinophyceae $18 \mathrm{~S}$ rDNA composition in the gut contents of I. racovitzai and $S$. thompsoni collected during ANT XXI/4. b. Comparison of the dinophyceae 18S rDNA composition in the gut contents of I. racovitzai collected across all four cruises (ANT XXI/4, ANT XXIII/2, ANT XXIV/2, ANT XXIII/6) to elucidate seasonal patterns. mismatch of the reverse primer to the 18S rRNA gene of salps, the PCR-amplification was strongly biased against the 18S rDNA sequence of salps. Less than $3 \%$ of the reads originated from salps, which were excluded from the analysis. The analyses revealed a highly similar composition of the sequence reads at higher taxonomic level. In all ten sequence libraries, the vast majority of the sequence reads $(c .70 \%)$ were affiliated with dinophyceae (Fig. 3). Sequences affiliating with diatoms from the genera Rhizosolenia sp., Thalassiosira sp., Nitzschia sp., Navicula sp., Fragilariopsis sp., Leptocylindrus sp. and Skeletonema sp. were found in the rare biosphere $(<1 \%$ of all sequence reads).

The read compositions from the gut contents of S. thompsoni specimens collected from the same sampling site were more similar to each other than to the gut contents of specimens from the other sites on the same cruise. The read compositions retrieved from gut contents of S. thompsoni and I. racovitzai collected at the same sampling site were different. At station 657, ciliate sequences were detected in the gut contents of $S$. thompsoni but not in I. racovitzai. A more detailed comparison of the dinoflagellate composition in the gut contents of salps collected during the autumn cruise revealed differences in the dinoflagellates ingested by $S$. thompsoni vs I. racovitzai (Fig. 4). The proportion of sequences annotated as 'uncultured dinoflagellate Typ 18' (contig 17) found in the gut contents of the I. racovitzai specimens was higher than in $S$. thompsoni. In contrast, the gut contents of $S$. thompsoni contained more sequences related to 'dinoflagellate group II' (e.g. contig 77) and 'uncultured dinoflagellate Typ 21' (contig 226) than I. racovitzai. At a higher taxonomic level, our data suggests that there is only a modest seasonal variation in the protist composition in the salp gut contents. However, significant differences in the ingested food composition were found between S. thompsoni and I. racovitzai at the species level.

\section{Discussion}

Salps are filter feeders, a non-selective feeding strategy that makes them dependent on the available food composition (Vargas \& Madin 2004). Previous microscopic studies have suggested that the phytoplankton composition found in the gut contents of salps reflect the ambient phytoplankton communities (Vargas \& Madin 2004, Tanimura et al. 2008). Even during winter time, when phytoplankton biomass is low, salps concentrate the chlorophyll and thus the phytoplankton in their guts (von Harbou et al. 2011). Microscopic examination of the salp gut contents suggested that the two species had similar diets, consisting mainly of diatoms, during both summer and autumn (von Harbou et al. 2011). On the 
contrary, cluster analysis of fatty acid compositions revealed a flagellate-based diet, with no significant seasonal variability, and differences in diet between the two salp species (von Harbou et al. 2011). Our study aimed to resolve the contradictory results from the microscopy and fatty acid analyses. We were able to obtain a sufficient number of salp samples enabling additional molecular studies of the salp gut contents. Clustering of the ARISA profiles confirmed the results of the fatty acid analyses. It showed a clear difference between $S$. thompsoni and I. racovitzai, but no significant seasonal variability. The statistical significance of seasonal variation could only be investigated in I. racovitzai. The ARISA profiles retrieved from the gut contents of I. racovitzai did not cluster according to sampling season, they grouped randomly in a distinct cluster that was significantly separated from the two other clusters consisting mainly of ARISA profiles retrieved from the gut contents of $S$. thompsoni. The ARISA profiles of the very limited number of seasonal samples of $S$. thompsoni display a strong clustering of this species in two major subgroups. One of the subgroups (Cluster II) contains exclusively ARISA profiles originating from the autumn study. The clustering could not be further related to any environmental data. These observations suggest that the $S$. thompsoni diet does not reflect the seasonal variation of phytoplankton and the strong relationship of phytoplankton to hydrographical fronts which have been recently demonstrated using the same molecular approach by Wolf et al. (2013).

Fatty acids are considered conservative tracers for the long-term dietary preferences of the consumer (Dalsgaard et al. 2003). During LAKRIS a higher proportion of flagellate markers than diatom markers were observed in the salps, which was opposite to microscopic observations of the gut contents (von Harbou et al. 2011). The authors proposed that digestion efficiencies might be responsible for this signal. However, sequencing of the gut contents of specimens of $I$. racovitzai and $S$. thompsoni collected in the autumn suggests that the fatty acid signature may reflect the actual composition of the ingested food. Although our sequencing data reveal the occurrence of diatoms in the gut content of the salps, the vast majority of sequence reads derived from the gut contents of both species were affiliated to the flagellates of the class dinophyceae. However, the relative number of sequences in an environmental $18 \mathrm{~S}$ rDNA sequence library only provides an estimate of the relative abundance of organisms in an environmental sample. Different taxonomic groups contain different copy numbers of ribosomal genes in their genomes (Zhu et al. 2005). In the future, re-analysing the samples via quantitative PCR might provide quantitative information on the phytoplankton composition in the salp gut contents. The sequence data are a reliable indicator for the presence of a taxon in a sample. Thus the current dataset shows that dinophyceae were a food item for salps, but the relative contribution of dinophyceae to the phytoplankton community in the salp gut contents might be different from the one indicated by pyrosequencing. Nevertheless, the high contribution of dinophyceae to the sequence libraries in this study is in agreement with the high occurrence of fatty acids indicative of dinophyceae, e.g. 18:4 (n-3) (Dalsgaard et al. 2003, von Harbou et al. 2011). Previous studies have also found dinoflagellates in salp diets in the Southern Ocean (Perissinotto et al. 2007). Heterotrophic dinoflagellates are considered to be an important member of the phytoplankton communities in the Southern Ocean, particularly during the winter (Garrison et al. 1993), and autotrophic dinoflagellates may contribute up to $25 \%$ of the protozoan assemblage in the summer (von Bodungen et al. 1988).

In summary, these observations suggest that, for salps, dinophyceae could be a major food source that is present in the water column throughout most of the year. The ability to use small flagellates, e.g. dinophyceae or cryptophyceae (Moline et al. 2004), as a major food source might be a competitive advantage for salps over krill in a changing Antarctic environment. To study the competition between the two species molecular studies and fatty acid composition of the ingested food of krill would be required.

The fatty acid 18:5 (n-3), indicative of prymnesiophytes (Nichols et al. 1991), was not observed in LAKRIS (von Harbou et al. 2011). Furthermore, Phaeocystis antarctica, the most abundant prymnesiophyte in the Southern Ocean, was not observed either (von Harbou et al. 2011). Therefore, it was not a concern that the reverse primer $690 \mathrm{R}$ did not perfectly amplify the $18 \mathrm{~S}$ rDNA of prymnesiophytes.

Even though ribosomal sequences retrieved from the gut contents of both salp species were dominated by dinophyceae, they displayed differences in composition. These differences probably account for the clustering of the ARISA profiles. Three phylotypes assigned to dinophyceae displayed significant differences in their contribution to the gut contents of $S$. thompsoni and I. racovitzai. However, it was not possible to annotate them even at genus level because the ribosomal databases currently contain only a limited set of sequences from taxonomically well-characterized reference cultures. The differences between the two species might be related to inhabiting different vertical or spatial niches in the water column (von Harbou et al. 2011). Nevertheless, our findings indicate that the co-occurring $S$. thompsoni and I. racovitzai had different diets.

The molecular data show concordance with the fatty acid data, indicating a year-round, high contribution of dinophyceae to the salp diet. It is probable that the flagellate fatty acid signature and the dinophyceae 
sequences identified in this study originated from small cells that were undetectable by microscopic assessment. These findings suggest that salps in the Lazarev Sea might not be relying solely on diatom blooms, which might give these filter feeders a competitive advantage in an ecosystem facing environmental change that is expected to impact the timing and extent of phytoplankton blooms. However, the number of ribosomal sequences retrieved from well-characterized reference cultures is currently not sufficient to provide information on cell size or to identify the species of the organisms related to the sequences detected in the salp gut contents. Thus there is an urgent need for projects that focus on the cultivation and taxonomic characterization of reference organisms that are related to the environmental sequences in the ribosomal databases. This would not only improve the phylogenetic annotation of ribosomal sequences, but also enable establishment of the cell size.

\section{Conclusions}

To our knowledge this is the first study that has applied molecular methods to investigate the gut contents of salps. Using ARISA patterns and 454-pyrosequencing of the V4-18S rDNA, we showed that dinophyceae (flagellates) contribute to the diet of $S$. thompsoni and I. racovitzai. Furthermore, there are strong differences in diet between the two co-occurring salp species and limited seasonality of ingested food. These findings support the previous study where fatty acid signatures indicated a flagellate-based diet.

\section{Acknowledgements}

This work was supported by the Deutsche Forschungsgemeinschaft (grant PE565/8_1) and funds of the Helmholtz Association for financing the Helmholtz-University Young Investigators Group PLANKTOSENS (VH-NG-500). We greatly thank the crew of RV Polarstern for excellent support during the work at sea. Furthermore, we thank Kerstin Oetjen for great technical assistance. Annegret Müller and Uwe John are acknowledged for excellent technical support of the fragment analysis. We also thank the reviewers for their valuable comments.

\section{Supplemental material}

A supplemental table will be found at http://dx.doi.org/ 10.1017/S0954102014000157.

\section{References}

Alldredge, A.L. \& Madin, L.P. 1982. Pelagic tunicates - unique herbivores in the marine plankton. Bioscience, 32, 655-663.
Atrinson, A., Siegel, V., Pakhomov, E. \& Rothery, P. 2004. Longterm decline in krill stock and increase in salps within the Southern Ocean. Nature, 432, 100-103.

Behnke, A., Barger, K.J., Bunge, J. \& Stoeck, T. 2010. Spatiotemporal variations in protistan communities along an $\mathrm{O}-2 / \mathrm{H} 2 \mathrm{~S}$ gradient in the anoxic Framvaren Fjord (Norway). FEMS Microbiology Ecology, 72, 89-102.

Dalsgand, J., St John, M., Kattner, G., Müller-Navarra, D. \& Hagen, W. 2003. Fatty acid trophic markers in the pelagic marine environment. Advances in Marine Biology, 46, 225-340.

Diez, B., Massana, R., Estrada, M. \& Pedros-Alio, C. 2004. Distribution of eukaryotic picoplankton assemblages across hydrographic fronts in the Southern Ocean, studied by denaturing gradient gel electrophoresis. Limnology and Oceanography, 49, $1022-1034$.

Dubischar, C.D., Pakhomov, E.A., von Harbou, L., Hunt, B.P.V. \& Bathmann, U.V. 2012. Salps in the Lazarev Sea, Southern Ocean: II. Biochemical composition and potential prey value. Marine Biology, 159, 15-24.

Dunbar, J., Ticknor, L.O. \& Kuske, C.R. 2000. Assessment of microbial diversity in four southwestern United States soils by $16 \mathrm{~S}$ rRNA gene terminal restriction fragment analysis. Applied and Environmental Microbiology, 66, 2943-2950.

Edgar, R.C., Haas, B.J., Clemente, J.C., Quince, C. \& Knight, R. 2011. UCHIME improves sensitivity and speed of chimera detection. Bioinformatics, 27, 2194-2200.

Finn, R.D., Clements, J. \& Eddy, S.R. 2011. HMMER web server: interactive sequence similarity searching. Nucleic Acids Research, 39, W29-W37.

Fraser, L., Strzezek, J. \& Kordan, W. 2011. Effect of freezing on sperm nuclear DNA. Reproduction in Domestic Animals, 46, 14-17.

GARrison, D.L., BuCK, K.R. \& Gowing, M.M. 1993. Winter plankton assemblage in the ice edge zone of the Weddell and Scotia Seas composition, biomass and spatial distributions. Deep-Sea Research Part I - Oceanographic Research Papers, 40, 311-338.

Joo, S., Lee, S.R. \& PARK, S. 2010. Monitoring of phytoplankton community structure using terminal restriction fragment length polymorphism (T-RFLP). Journal of Microbiological Methods, 81, $61-68$

Kunin, V., Engelbrektson, A., Ochman, H. \& Hugenholtz, P. 2010. Wrinkles in the rare biosphere: pyrosequencing errors can lead to artificial inflation of diversity estimates. Environmental Microbiology, 12, 118-123.

Margulies, M., Egholm, M., Altman, W.E. et al. 2005. Genome sequencing in microfabricated high-density picolitre reactors. Nature, 437, 376-380.

Matsen, F.A., Kodner, R.B. \& Armbrust, E.V. 2010. pplacer: linear time maximum-likelihood and Bayesian phylogenetic placement of sequences onto a fixed reference tree. BMC Bioinformatics, 11, 10.1186/1471-2105-11-538.

Medlin, L.K., Metfies, K., Mehl, H., Wiltshire, K. \& Valentin, K. 2006. Picoeukaryotic plankton diversity at the Helgoland time series site as assessed by three molecular methods. Microbial Ecology, 52, 53-71.

Mendes, C.R.B., Tavano, V.M., Leal, M.C., de Souza, M.S., Brotas, V. $\&$ GARCIA, C.A.E. 2013. Shifts in the dominance between diatoms and cryptophytes during three late summers in the Bransfield Strait (Antarctic Peninsula). Polar Biology, 36, 537-547.

Metfies, K., Gescher, C., Frickenhaus, S., Niestroy, R., Wichels, A., Gerdts, G., Knefelkamp, B., Wiltshire, K. \& Medlin, L. 2010. Contribution of the class cryptophyceae to phytoplankton structure in the German Bight. Journal of Phycology, 46, 1152-1160.

Metfies, K. \& Medlin, L.K. 2008. Feasibility of transferring fluorescent in situ hybridization probes to an 18S rRNA gene phylochip and mapping of signal intensities. Applied and Environmental Microbiology, 74, 2814-2821. 
Moline, M.A., Claustre, H., Frazer, T.K., Schofield, O. \& Vernet, M. 2004. Alteration of the food web along the Antarctic Peninsula in response to a regional warming trend. Global Change Biology, 10, 1973-1980.

Nichols, P.D., Skerratt, J.H., Davidson, A., Burton, H. \& McMeerin, T.A. 1991. Lipids of cultured Phaeocystis pouchetii signatures for food-web, biochemical and environmental studies in Antarctica and the Southern Ocean. Phytochemistry, 30, 3209-3214.

Nickrent, D.L. \& Sargent, M.L. 1991. An overview of the secondary structure of the V4-region of eukaryotic small subunit ribosomal RNA. Nucleic Acids Research, 19, 227-235.

Nicol, S., Worby, A. \& Leaper, R. 2008. Changes in the Antarctic sea ice ecosystem: potential effects on krill and baleen whales. Marine and Freshwater Research, 59, 361-382.

Ono, A. \& Moteкi, M. 2013. Spatial distributions and population dynamics of two salp species, Ihlea racovitzai and Salpa thompsoni, in the waters north of Lutzow-Holm Bay (East Antarctica) during austral summers of 2005 and 2006. Polar Biology, 36, 807-817.

Pakhomov, E.A., Dubischar, C.D., Strass, V., Brichta, M. \& Bathmann, U.V. 2006. The tunicate Salpa thompsoni ecology in the Southern Ocean. I. Distribution, biomass, demography and feeding ecophysiology. Marine Biology, 149, 609-623.

Pakhomov, E.A., Froneman, P.W. \& Perissinotto, R. 2002. Salp/krill interactions in the Southern Ocean: spatial segregation and implications for the carbon flux. Deep-Sea Research Part II - Topical Studies in Oceanography, 49, 1881-1907.

Pakhomov, E.A., Hall, J., Williams, M.J.M., Hunt, B.P.V. \& Stevens, C.J. 2011. Biology of Salpa thompsoni in waters adjacent to the Ross Sea, Southern Ocean, during austral summer 2008. Polar Biology, 34, 257-271.

Perissinotto, R., Mayzaud, P., Nichols, P.D. \& Labat, J.P. 2007. Grazing by Pyrosoma atlanticum (Tunicata, Thaliacea) in the south Indian Ocean. Marine Ecology Progress Series, 330, 1-11.
Smetacek, V., Assmy, P. \& Henjes, J. 2004. The role of grazing in structuring Southern Ocean pelagic ecosystems and biogeochemical cycles. Antarctic Science, 16, 541-558.

Tanimura, A., Kawaguchi, S., Oka, N., Nishikawa, J., Toczko, S., Takahashi, K.T., Terazaki, M., Odate, T., Fukuchi, M. \& Hosie, G. 2008. Abundance and grazing impacts of krill, salps and copepods along the 140 degrees E meridian in the Southern Ocean during summer. Antarctic Science, 20, 365-379.

Tobe, K., Meyer, B. \& Fuentes, V. 2010. Detection of zooplankton items in the stomach and gut content of larval krill, Euphausia superba, using a molecular approach. Polar Biology, 33, 407-414.

VARGAS, C.A. \& Madin, L.P. 2004. Zooplankton feeding ecology: clearance and ingestion rates of the salps Thalia democratica, Cyclosalpa affinis and Salpa cylindrica on naturally occurring particles in the Mid-Atlantic Bight. Journal of Plankton Research, 26, 827-833.

Von Bodungen, B., NoËthig, E.M. \& SuI, Q. 1988. New production of phytoplankton and sedimentation during summer 1985 in the south eastern Weddell Sea. Comparative Biochemistry and Physiology Part B: Comparative Biochemistry, 90, 475-487.

von Harbou, L., Dubischar, C.D., Pakhomov, E.A., Hunt, B.P.V., Hagen, W. \& Bathmann, U.V. 2011. Salps in the Lazarev Sea, Southern Ocean: I. Feeding dynamics. Marine Biology, 158, 2009-2026.

Woese, C.R. 1987. Bacterial evolution. Microbiological Reviews, 51, 221-271.

Wolf, C., Frickenhaus, S., Kilias, E.S., Peeken, I. \& Metfies, K. 2013. Regional variability in eukaryotic protist communities in the Amundsen Sea. Antarctic Science, 25, 741-751.

Zhu, F., Massana, R., Not, F., Marie, D. \& Vaulot, D. 2005. Mapping of picoeucaryotes in marine ecosystems with quantitative PCR of the 18S rRNA gene. FEMS Microbiology Ecology, 52, 79-92. 